\title{
Prevenção às DSTIAIDS no ambiente escolar
}

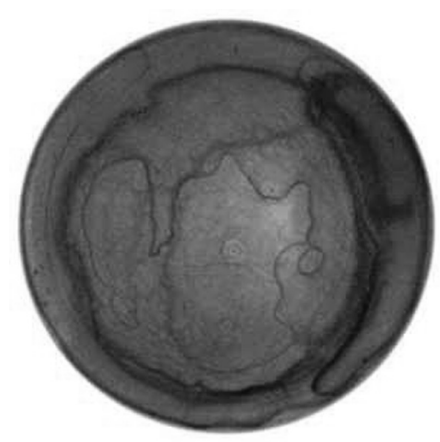

Angélica Fonseca 1

FONSECA, A. Prevention of Sexually Transmitted Diseases and AIDS in the school environment, Interface Comunic, Saúde, Educ, v.6, n.11, p.71-88, 2002.

This article largely reflects upon projected expectations regarding educational actions/activities carried out in schools, within the scope of STD/AIDS prevention. To discuss this theme we revised historical aspects that marked the institution of Sexual Education as a school subject. We noticed a significant association between school and the objective of correcting human behavioral deviations, including sexual (mis)conduct. We also observed that the proposals for Health Education, formulated in the health field and targeting schools, establish principles, objectives and recommendations for the sexual education of adolescents and children that do not take school as a social environment as their theme. We concluded by pointing out that highly constructive contributions are likely to be developed at schools, mainly as a result of the ability to broach the apparently fixed categories that constitute the field of sexual experience as eminently historical constructions. We believe that, from this point of view, the possibility of rearranging social relations is strengthened. These social relations can have an impact on the conditions that enhance the vulnerability of individuals to sexually transmitted diseases.

KEY WORDS: Acquired immunodeficiency syndrome; sexually transmitted disease; sex education; student health services.

A reflexão central deste artigo constitui-se em torno das expectativas projetadas em relação às ações educativas desenvolvidas em escolas no âmbito da prevenção as Doenças Sexualmente Transmissíveis /Aids. Para discutir este tema recorremos à revisão dos aspectos históricos que marcaram a instituição da educação sexual como conteúdo escolar. Registramos uma intensa associação entre a escola e o objetivo de corrigir os desvios da conduta humana, aí incluídos os de ordem sexual. Observamos, ainda, que as propostas de educação em saúde formuladas no campo da saúde e dirigidas à escola estabelecem princípios, objetivos e recomendações para a educação sexual de adolescentes e crianças sem tematizar a escola como espaço social. Concluímos, assinalando que contribuições altamente construtivas e passíveis de serem desenvolvidas na escola se dão, sobretudo, pela capacidade de abordar as categorias aparentemente fixas que constituem o campo da experiência da sexualidade como construções eminentemente históricas. Acreditamos que a partir desse viés acentua-se a possibilidade de rearranjo de relações sociais que podem gerar impacto sobre as condições que ampliam a vulnerabilidade dos indivíduos em relação às doenças sexualmente transmissíveis.

PALAVRAS-CHAVE: Síndrome de imunodeficiência adquirida; doenças sexualmente transmissíveis; educação sexual; serviços de saúde para estudantes.

${ }_{1}^{1}$ Professora-pesquisadora da Escola Politécnica de Saúde Joaquim Venâncio, Fundação Oswaldo Cruz (Fiocruz); Sanitarista do Programa de DST/Aids da Secretaria Municipal de Saúde do Rio de Janeiro. <afonseca@malaria.procc.fiocruz.br> 
FONSECA, A.

\section{Apresentação}

Que expectativas podemos ter em relação às ações educativas desenvolvidas em escolas no âmbito da prevenção às Doenças Sexualmente Transmissíveis (DST)/Aids?

Na construção dessa reflexão observamos que as propostas de educação em saúde gestadas no campo da saúde e dirigidas à escola estabelecem princípios, objetivos, recomendações para a educação sexual de adolescentes e crianças sem, contudo, tematizar a escola como espaço social. Trata-se de uma produção que raramente se detém em discutir qual a especificidade da escola, como as teorias pedagógicas se relacionam com essas propostas educativas e, desse modo, a escola passa a ser uma categoria homogênea.

Esse equívoco estende-se e não raramente nos deparamos com um conceito de adolescente, construído a partir da Psicologia e da Biologia, que se pretende explicativo de uma ampla categoria, a dos adolescentes, dando origem a enunciados que se transformam em clichês, tais como 'Adolescentes gostam de testar seus limites e pouco refletem sobre riscos'.

A relação entre o ensino escolar e as questões de saúde torna-se ainda mais complexa com o ingresso, nessa cena, do discurso epidemiológico que oferece, na forma de dados estatísticos de morbi-mortalidade, argumentos irrefutáveis sobre a importância de definir a escola como espaço de prevenção em saúde.

Modelos teóricos ancorados em diversas disciplinas trazem os conceitos, os mais presentes, que constituem o idioma da prevenção: desenvolvimento de habilidades; mudança de comportamento; riscos e danos, protagonismo juvenil; vulnerabilidade. E assim, diante do peso de verdades científicas tão propriamente apresentadas cabe aos professores cumprir seu papel, o que freqüentemente, limita-se a experiências extremamente pontuais, cuja principal marca é o voluntarismo pessoal de seus formuladores $e$ executores.

Neste trabalho, pretendemos retomar algumas dessas questões, sinalizando que as contribuições passíveis de serem desenvolvidas na escola se dão, sobretudo, pela capacidade de abordar as categorias aparentemente fixas que constituem o campo da experiência da sexualidade como construções eminentemente históricas. Acreditamos que, a partir desse enquadramento, acentua-se a possibilidade de um novo arranjo das relações sociais, gerando impacto sobre as condições que ampliam a vulnerabilidade em relação às doenças sexualmente transmissíveis.

"Não se abre à força um botão de rosa, sobretudo com as mãos sujas": revendo a história da educação sexual

Quando em 1970, a Comissão Nacional de Moral e Civismo registrou a frase acima em parecer contrário à aprovação de um projeto de lei que pretendia estabelecer a obrigatoriedade da educação sexual nas escolas, sintetizava assim alguns elementos ainda hoje importantes no

2 Projeto de Lei de 1968 da deputada carioca Júlia

Steimbruck. pensamento sobre a relação entre sexualidade e educação.

Sobressai nessa metáfora, uma concepção de sexualidade aliada à 
imoralidade (mãos sujas) tida também como uma dimensão da vida em que as crianças, associadas aos seres puros da natureza (botão de rosa), estariam preservadas. Por fim, situa a educação sexual como um ato de violência.

Esse pensamento, atrasado 65 anos em relação aos estudos pioneiros em que Freud nos apresentava a sexualidade como algo inerente ao ser humano $e$, na criança, como uma manifestação indiscutível de atividade intelectual, mostrou-se em plena sintonia com as primeiras referências que unem a educação à sexualidade. Os movimentos iniciais de articulação desses dois campos conduzem-nos à França do século XVIII, quando a preocupação com a repressão à sexualidade infantil, representada pelo controle à masturbação, desenhou uma educação anti-sexual (Barroso \& Bruschini, 1990).

Apesar desses registros anteriores, pode-se tomar o século XIX como um marco histórico, quando, na Europa, as questões sobre a sexualidade passaram a extrapolar os espaços religiosos para tornarem-se alvo de discussão e de regulação pública em diversas partes do mundo. Neste momento, a moral vitoriana dava contornos a uma situação bastante contraditória na qual as mulheres aprendiam, também por meio da escola, a manterem-se puras e os homens gozavam de grande liberdade sexual, por meio de uma extensa rede de prostituição. Era exclusivamente sobre as mulheres (as puras e as prostitutas) que recaíam as iniciativas de controle da sexualidade com objetivo final de preservar a saúde, ameaçada pela freqüência de doenças sexualmente transmissíveis (Weeks, 1999).

A sexologia nascia nesse momento como disciplina, contendo uma referência múltipla de formação que incorporava a Biologia, a Psicologia, a Antropologia, a Sociologia e a História. Entretanto, o que parece possível abstrair-se dos encaminhamentos gerados a partir de estudos sobre a sexualidade é que todas as disciplinas adjacentes, convergiam para a conformação de um objeto que era, sobretudo, biologizado. Apresentada por um importante sexólogo da época, Kraff-Ering como um instinto de força incontrolável, a sexualidade aparecia como verdade última sobre os indivíduos. Assim, os diversos especialistas que se dedicavam à questão, detinham-se na classificação dos tipos de indivíduos "vis-à-vis" os tipos sexuais (Weeks, 1999).

A relação entre essa forma de elaborar a sexualidade e o exercício do poder foi o que, no entender de Foucault (1988), desenhou quatro espaços de controle associados a quatro tipos de personalidade: a sexualidade feminina /a mulher histérica; a sexualidade infantil /a criança masturbadora; o controle da reprodução / o casal que usa contracepção; o normal / o homossexual. Assim, as instituições, quer fossem do campo jurídico, quer da educação e saúde, atuavam no controle da sexualidade a fim de orientá-la, reprimi-la ou condená-la em função dos padrões de normalidade então concebidos. Era precisamente essa concepção do espaço da educação sexual como adequado à prescrição da experiência saudável e a restrição da experiência classificada como não saudável, que exprimia sua origem notadamente higienista.

O século seguinte teve início, confirmando o status de pensamento do século XIX e acrescentando novas preocupações, particularmente ao campo 
da reprodução, denominada de transmissão da vida. A educação sexual mantinha estreita aproximação com os projetos eugenistas, que claramente sustentavam a perspectiva de aprimoramento da raça branca (Sayão, 1997)

Aos professores que se envolviam com a questão da sexualidade, buscando pensá-la de forma mais abrangente, eram dirigidas acusações, cujo texto de Maurice Biglow de 1916 (apud Britzman, 1999, p.95) contém exemplarmente o espírito da época:

Certos homens e mulheres neuróticos e histéricos, aos quais falta um treinamento fisiológico completo e cujos próprios distúrbios sexuais os têm levado a devorar de forma omnívora e pouco científica a literatura psicopatológica sobre sexo, de autores tais como Havelock Elis, Krafft-Ebing e Freud, são provavelmente professores pouco seguros em termos de higiene sexual.

As ações que viriam punir os docentes, considerados ameaçadores ao convívio com crianças e jovens, estenderam-se por décadas. Em 1930, no Brasil, um professor de Biologia, que incluiu no currículo de sua disciplina o papel da mulher na reprodução foi processado e demitido. Com efeito, esse caso não foi uma exceção, havendo registros de punições semelhantes no Rio de Janeiro no final dos anos 1960.

Os movimentos de construção de um espaço para lidar com a sexualidade que escapasse ao âmbito biológico atingiam figuras ilustres como Berta Lutz que, ainda na década de 1920, propôs a educação sexual com objetivos de proteger a infância e a maternidade (Sayão, 1997). Esse conflito, entre uma sociedade predominantemente conservadora, mas com movimentos intensos de modernização, transpareceu na incapacidade de produzir um consenso sobre os conteúdos e metodologias para a abordagem do tema. Esse fato, aliado à militância da Igreja Católica contrária a essa discussão, determinou a exclusão do tema 'educação sexual' do debate educativo, delineando um tempo de omissão oficial no período entre os anos 1930 e 1960.

O clima de transformação de valores comportamentais, intensamente influenciado pelas conquistas do movimento feminista reconduziu a questão da educação sexual ao debate com um novo enfoque menos normativo e mais crítico em relação à formação de valores. Durante a década de 1960, na região Sudeste, diversas escolas das redes pública e privada implementaram experiências com programas que incorporavam, inclusive, os pais de alunos.

Mas não seria justamente a educação sexual, numa formatação menos repressora, que ficaria livre dos efeitos do regime político que se instalara no país. Assim, aconteceram retrocessos em relação às experiências em curso, além da coibição de novas propostas, inclusive das que regulamentavam a educação sexual. Um fato marcante foi o veto à lei da deputada Júlia Steimbruck, à qual já nos referimos anteriormente.

Em meados dos anos 1970, o controle da reprodução que, há tanto tempo antes, já oferecera argumentos para a educação sexual sob a forma de controle da natalidade, vinha mais uma vez reinserir a educação sexual na 
${ }^{3}$ Nos Parâmetros

Curriculares Nacionais, a questão da

sexualidade faz parte do tema transversal "Orientação Sexual".

Contudo, entre autores que discutem a sexualidade essa expressão é utilizada para caracterizar a relação entre o sujeito e o seu objeto de desejo, falando-se de orientação

heterossexual, por exemplo. Quando assunto em pauta é a construção de saberes no âmbito da

sexualidade, preserva-se a denominação 'educação sexual'. arena do debate escolar. A posição ambígua do poder público, quanto à inclusão ou não do tema nos currículos escolares traduzia-se de forma quase caricata, tal como aconteceu quando a Secretaria Estadual de Educação de São Paulo impediu a oficialização da Educação Sexual nas escolas, no mesmo ano (1975) em que registrou o tema como conteúdo curricular dos programas de saúde dessa mesma secretaria.

Ora, devemos, então, argüir o que viria finalmente dar limites a essa ambigüidade e estabelecer a educação sexual como um tema escolar? Certamente é um equívoco buscar um único fator, mas no conjunto de fatores que interagem para a definição dessa situação, identificamos a pressão exercida por professores e alunos, que mostravam profundo interesse pelo tema, assim como o impulso inigualável dado pelo surgimento da Aids e de casos cada vez mais freqüentes de gravidez na adolescência. Assim, vimos fortalecido e atualizado o vínculo que, desde o século XIX, estruturou-se entre a prevenção de doenças e a educação sexual. Ante o medo que a convivência com uma doença letal instalou na população $e$ a delimitação das doenças sexualmente transmissíveis/Aids como alvos de ações multidisciplinares, a escola passou a ser identificada como uma instituição social de participação indispensável nesse projeto de saúde preventiva. Uma pesquisa do Instituto DataFolha de 1993, realizada em dez capitais brasileiras, demonstrava que $86 \%$ da população era favorável à inclusão da Educação Sexual nos currículos escolares (Brasil, 1998a)

Entretanto, seria incorreto situar o momento atual da educação sexual como uma continuidade dos momentos anteriores. Em primeiro lugar, o sistema educacional brasileiro, como efeito das modificações ocasionadas pela nova Lei de Diretrizes e Bases (LDB) da Educação, passa por uma reforma que atinge a forma de conceber o ensino e o currículo; repercutindo sobre a escola como um todo. Em segundo lugar, a Educação Sexual ${ }^{3}$ foi um dos temas selecionados para compor os Temas Transversais dos Parâmetros Curriculares Nacionais- PCN (Brasil, 1998b), os demais são Ética, Trabalho e Consumo, Meio Ambiente, Pluralidade Cultural e Saúde.

É necessário assinalar que essa separação dos temas, Orientação Sexual e Saúde, vale para demarcar a inserção da sexualidade em um campo mais complexo de interações, onde estão presentes as Ciências Humanas, Sociais e as da Linguagem. Por último, a produção de teorias em torno desta questão originou novos conceitos, configurando práticas que já começam a alterar o panorama da Educação Sexual nas escolas.
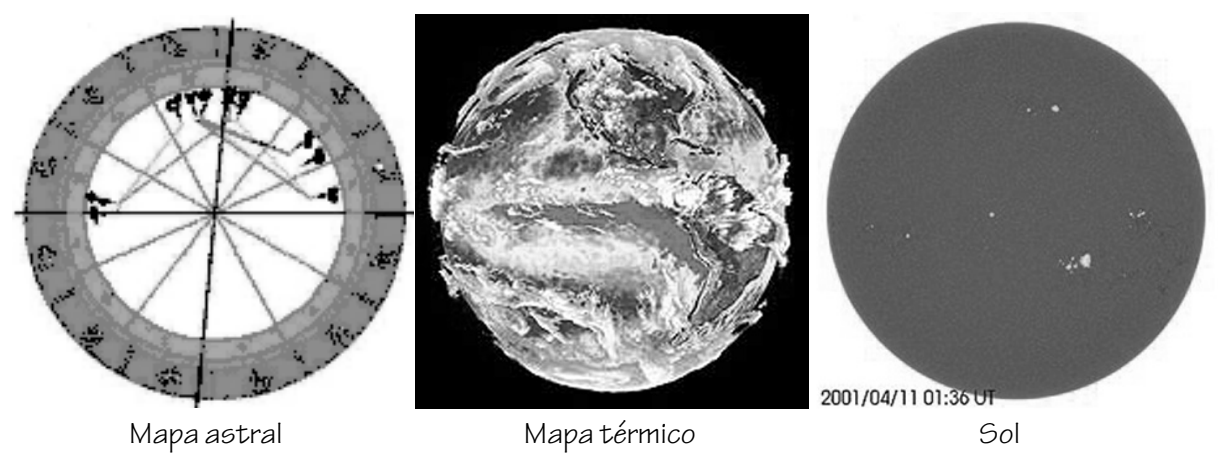

Interface - Comunic, Saúde, Educ, v6, n11, p.71-88, ago 2002 
Aprofundar a reflexão sobre a sexualidade como construto histórico é o aspecto nuclear da proposta de educação sexual que discutiremos posteriormente. Compreendemos que, embora não tenhamos aqui a possibilidade de realizar uma extensa revisão histórica, devemos assinalar algumas condições visíveis que marcam a produção de alternativas práticas, conceituais e atuais das propostas de Promoção à Saúde Sexual nas escolas.

Grande parte do material a que tivemos acesso tinha como questão central a educação sexual relacionada à prevenção, notadamente das DST/ Aids e do uso de drogas.

Acreditamos, porém, que a facilidade de acesso a publicações com esse enfoque não deve ser tomada como um dado casual, mas sim, de forma importante, como reflexo dos recursos financeiros investidos no país sob a égide da prevenção às DST/Aids. O resultado concreto é a realização de pesquisas, seminários, congressos, além da edição de enumerável material educativo. Diversos financiamentos de organismos internacionais promovem abordagens metodológicas a partir, sobretudo, das formas de avaliação convenientes aos projetos.

Entre as abordagens teóricas mais comumente tomadas como referência para o trabalho educativo de prevenção em saúde, particularmente de DST/ Aids, identificamos três que merecem destaque: 1) Modelo de Crenças em Saúde (Health Believ Model); 2) Abordagem Baseada na Razão (Situated Rationality Approach); 3) Comportamento de Risco como Produto Social (Gabe, 1995).

O Modelo de Crenças em Saúde -HBM é o mais difundido no campo de prevenção às DST/Aids. É classificado como um modelo psicossocial e tem em Kurt Lewin ${ }^{4}$ a sua principal referência teórica. A partir desse modelo compreende-se o comportamento de risco como parte de uma rede de percepções encadeadas em quatro etapas. Na primeira, o indivíduo deve perceber-se sob risco; na segunda, o problema deve ser valorizado em termos de gravidade; na terceira, os mecanismos de prevenção devem ser reconhecidos como efetivos e, por fim, o indivíduo deve estar disposto à adoção de medidas preventivas.

Essa perspectiva fundamenta os incontáveis trabalhos de pesquisa que partem de inquéritos, focalizando tanto as questões de comportamento, como as percepções dos indivíduos perante diversas situações de risco potencial. A categoria comportamento de risco é estruturante desse pensamento $e$ as etapas descritas originam propostas de educação em saúde fortemente assimiladas pelo campo da saúde.

Associam-se a esse modelo, as ações que consideram a produção de temor em relação à atividade sexual, um mecanismo relevante do processo educacional. O medo de adoecer seria um sentimento que promoveria os comportamentos desejáveis em relação as duas primeiras etapas e, também, geraria um efeito em relação à última etapa. Para as etapas três e quatro, ganham peso as estratégias de marketing em torno dos mecanismos concretos de prevenção até o momento, prioritariamente, o preservativo masculino.

\footnotetext{
${ }^{4}$ Kurt Lewin é

reconhecido como o

fundador da moderna

Psicologia Social. Seus principais trabalhos, publicados nas décadas de 1930 e 1940 , enfatizavam a compreensão dos problemas psicológicos a partir das interações sociais. Ficou particularmente conhecido pelo pioneirismo no desenvolvimento de dinâmicas de grupo, posteriormente adotadas em diversas áreas, entre elas a Educação e a Saúde. Foi o criador do Centro de Pesquisa de Dinâmicas de Grupo do MIT (Massachusetts's Institute of Technology).
} 
De um ponto de vista mais geral, a informação ganha centralidade, devendo ser especialmente valorizada aquela que provoca mais resultado na promoção de uma percepção de risco. Assim, dados epidemiológicos apresentados pelo viés do impacto, imagens de pessoas doentes por um lado e por outro, a apresentação do preservativo como artefato da moda tornamse métodos de trabalhar a educação para a prevenção. Nesta perspectiva, as oficinas de sexo mais seguro, por exemplo, embora tentem transcender esses limites, são experiências filiadas a essa vertente.

Os objetivos intermediários mais importantes são informar para o desenvolvimento de habilidades; repassar instruções e facilitar o acesso aos recursos materiais para a prevenção (Eliane, 1999; WHO,1998) com o objetivo final de uma mudança de comportamento.

Um aspecto crítico desse modelo refere-se ao fato de compreender o comportamento como um evento linear e dependente apenas da vontade individual.

O segundo modelo, Abordagem Baseada na Razão, também está centrado na perspectiva individual e objetiva fazer um contraponto com as teorias que identificam o engajamento em comportamentos de risco como um fenômeno irracional. Nos estudos dessa corrente, busca-se construir um sentido racional, a partir da decomposição das motivações atribuíveis às atitudes que direcionam determinados grupos de pessoas a esses comportamentos. Do ponto de vista metodológico, os estudos são qualitativos e pretendem compreender situações específicas tal como o que leva um homem que faz sexo com homens manter relações sexuais protegidas com parceiros eventuais e desprotegidas com o parceiro regular.

Ambos os modelos, por desenvolverem uma análise na perspectiva exclusivamente individual, mostram-se bastante limitados como auxiliares a uma reflexão sobre comportamentos sexuais que considerem a questão do poder como uma categoria de análise relevante.

O terceiro modelo considera que os comportamentos de risco são produtos de relações culturais. Nesse modelo, o termo "relações culturais" exprime não a idéia de formações sociais, mas, de grupos. De acordo com a antropóloga Mary Douglas, que desenvolveu essa visão de comportamento de risco, as variações que envolvem a avaliação de risco e a resposta ao risco são produtos de diferentes socializações em subculturas e complexas redes institucionais. Os comportamentos, então, ocorrem em função de variações dos grupos aos quais os indivíduos pertencem, além dos padrões de constrangimento impostos pelo grupo. O esquema que orienta a categorização de comportamentos é representado por duas linhas que se cruzam (em formato de cruz), em que o eixo " $x$ " representa o grau de integração do indivíduo ao grupo e o " $y$ " o grau de aderência que o grupo exige para cada comportamento. Diferentes situações delineiam-se: a individualista, a fatalista, e uma terceira que estaria em um ponto intermediário.

A engenhosidade do esquema proposto para simplificar a compreensão de comportamentos, chama-nos atenção, cabendo perguntar: se um indivíduo só pode receber influências de um único grupo; ou, por meio de raciocínio inverso, se um determinado grupo estabelece uma mesma norma de 
conduta para todos os indivíduos.

Por mais que esteja presente a intenção de não restringir à dimensão individual todos os fatores que se entrelaçam, gerando comportamentos, identificamos uma propensão à produção de estereótipos grupais.

Alterando o panorama das abordagens individuais/grupais e contribuindo para a compreensão das questões de saúde articuladamente às de cidadania, encontramos o conceito de vulnerabilidade (Mann et al.,1993; Ayres,1996). Esse conceito não é uma mera substituição do conceito de risco, nem é complementar a esse. Trata-se de uma construção motivada pela necessidade de mudar os referenciais conceituais ante a constatação de que as ações preventivas colocadas nestes termos (comportamento de risco) já são concebidas de forma limitada.

$\mathrm{O}$ aspecto fundamental do conceito de vulnerabilidade é que esse apresenta um pensamento sobre a prevenção, recusando uma abordagem redutivista, na qual a intervenção preventiva é apenas uma questão de atitude individual. Tal lógica faz de cada indivíduo em particular, um culpado em potencial. Contrapõe-se a isso valorizando as questões sociais $e$, destacando que, em relação ao HIV, as pessoas infectam-se:

não porque individualmente assumam comportamentos de risco, queiram correr riscos, desejam se expor ao vírus... $\mathrm{O}$ comportamento tem a ver com o modo como as pessoas estão vivendo, como elas se reproduzem socialmente, que tipos de bens sentem necessitar, como geram os bens de que necessitam, como os distribuem e compartilham, como usufruem deles.

(Ayres, 2000, p. 24)

Se optarmos por excluir do campo semântico da prevenção às DST/Aids a noção de grupo de risco e de comportamento de risco em favor do conceito de vulnerabilidade, devemos, então, construir novos objetivos e práticas mais coerentes com esse contexto.

Esses novos objetivos consideram que as pessoas não têm a mesma possibilidade de transformação da sua realidade e, portanto, de adotar medidas preventivas. Desloca-se a posição do educador (esteja no serviço de saúde ou na escola) do lugar autoritário de quem determina quais são os comportamentos adequados e estabelece a censura aos indivíduos que não os adotam. Contrariando esse movimento, o que se deseja estabelecer é uma relação dialógica em que as alternativas de prevenção possam ser construídas paralelamente ao processo de ampliação de cidadania.

A análise de vulnerabilidade parte do pressuposto de que os indivíduos não são culpados, mas têm também responsabilidade e capacidade de transformação da sua própria história. Categorias como "população alvo" são igualmente rechaçadas, pois o fundamental é que os indivíduos sejam partícipes do processo de prevenção. A noção de processo surge para confirmar o fato de que não existe um ponto final dado a priori, mas a combinação de possibilidades que vão se efetivando ou não, renovando-se, sendo reconsideradas em um caráter dinâmico que propõe ao educador uma postura de companheirismo nessa construção. 
A informação atualizada, o "marketing" de preservativos, o desenvolvimento de habilidades não ficam sem lugar nessa concepção de educação. Embora sejam reconhecidas como condições que podem favorecer a transmissão/prevenção, elas perdem o lugar de protagonistas para a análise das situações e condições mais gerais de vida de cada coletividade, levando a uma reflexão que consiga expandir as oportunidades para a busca da felicidade com menos riscos.

\title{
De qual escola falamos?
}

A questão que nos impomos aqui é sobre o modo pelo qual implicamos a Escola na produção de um projeto de prevenção que tem como referência o conceito de vulnerabilidade.

Essa discussão remete-nos à própria concepção de escola com a qual estamos lidando. Adotar o conceito de vulnerabilidade leva-nos a reconhecer que não existe o adolescente como uma categoria homogênea, tampouco isso se aplica à escola.

Vale, então, perguntar que especificidade tem a escola e, tendo por base essa resposta, argüir quais as melhores articulações dessa escola com a educação sexual, pensando na promoção à saúde.

É inevitável interrogarmo-nos sobre o que tem precedência: a definição de propósitos para a escola $e$, portanto, os conteúdos que lhe são pertinentes ou a definição de conteúdos para a definição do papel da escola?

A resposta não é simples, e o melhor caminho parece-nos que é apostar em um processo dialético em que optamos por definir uma especificidade para a escola, considerando que isso não significa fechar a escola para o novo.

Quanto aos propósitos da escola, recorremos à fala de Demerval Saviani (1999) que se destaca no campo das teorias pedagógicas como o principal pensador brasileiro da Teoria Crítica dos Conteúdos.

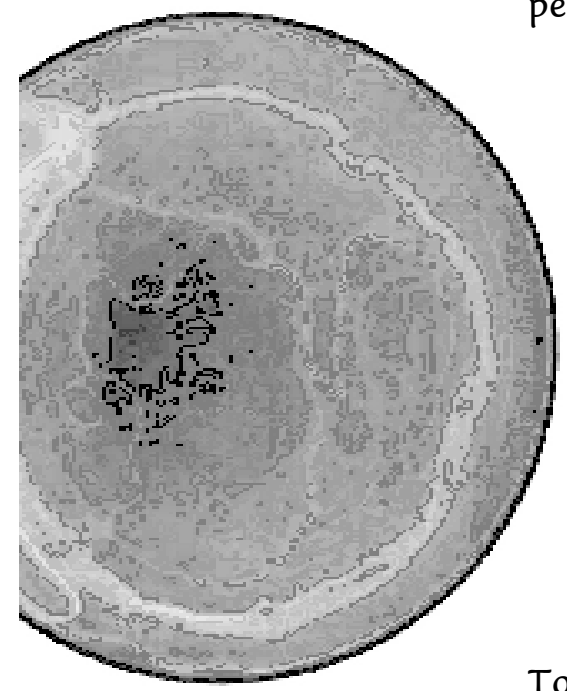

\author{
A Escola deve propiciar a aquisição de instrumentos que \\ possibilitam o acesso ao saber elaborado (ciência), bem como aos \\ rudimentos desse saber. (p.23) \\ E ainda, \\ a compreensão da natureza da educação enquanto um trabalho \\ não-material, cujo produto não se separa do ato de produção nos \\ permite situar a especificidade da educação como referida aos \\ conhecimentos, atitudes, hábitos, símbolos sob aspecto de \\ elementos necessários à formação da humanidade em cada \\ indivíduo singular, na forma de uma segunda natureza que se \\ produz, deliberada e intencionalmente, através de relações \\ pedagógicas historicamente determinadas... (p.29)
}

Tomando essa referência, consideramos que a escola estaria, em primeiro lugar, comprometida com a transmissão do saber escolar, que remete ao saber objetivo disponível na cultura, assegurando a socialização desse saber, identificado como instrumento para a intervenção social do cidadão 
consciente.

Assim, o fato de a Educação Sexual aparecer na Lei de Diretrizes e Bases da Educação (lei 9.394/96) como um tema a ser inserido transversalmente no currículo dos ensinos fundamental e médio, indicaria a propriedade do tema ser posto em análise pelas próprias instituições de ensino com o propósito de estabelecer o modo mais consistente de abordá-lo.

Fortalecendo essa proposição, incide o fato de que não existe uma definição de currículo que revele uma verdade sobre o que é o currículo, o que existe são perspectivas teóricas, expressando posicionamentos diferentes. De acordo com Silva (1999), as teorias críticas e pós-críticas situam o currículo no campo político de articulação de algumas questões: o que deve ser ensinado? Em que eles ou elas devem tornar-se?

Essas questões apontam para o aspecto da formação de identidade $e$ subjetividade que consiste no núcleo da discussão sobre currículo. Saviani (1999) chama atenção para o fato de que, se tudo é pertinente no currículo, então, todos os temas acabam por ganhar o mesmo peso, criando inversões que descaracterizam o trabalho escolar.

Retornando ao nosso tema específico, cabe perguntar se a educação sexual é um tema que merece inclusão no currículo e de que forma isso pode ocorrer sem tornar inespecífica a escola e sim, reforçando seu lugar de instituição social ampliadora das capacidades humanas, a fim de intervir na formação de subjetividade e nas condições concretas de transformação do seu espaço social.

Reflexões e práticas bastante diversas têm oferecido um panorama dinâmico sobre o assunto, mas podemos identificar a existência de variações em torno de três eixos. O primeiro, ao qual se alinham alguns psicanalistas (Guirado,1999; Mendonça Filho,1999) parte do princípio de que o sexual não é de fato matéria que se preste ao educável e, portanto, não é desejável ter objetivos prévios em relação ao tema.

A escola seria o espaço para deixar que a sexualidade fluísse para depois tomá-la em consideração. Admitindo que a sexualidade necessariamente aflora, a escola cumpriria seu papel, se, nas práticas escolares, pela aprendizagem posta por disciplinas regulares, surgissem ocasiões para que ocorra a 'vontade de conhecer'.

Outras práticas mais sensíveis aos apelos da saúde pública buscam transmitir os conhecimentos fundamentais, relacionados a atividades sexuais, DST/Aids e o fazem por meio de inserções de ações educativas de curta duração com que freqüentemente contam com convidados que proferem palestras, realizam dinâmicas etc. Exemplos desses movimentos são as experiências relatadas na publicação "A prevenção na escola: relato de experiências" (São Paulo, 1999).

No terceiro eixo, estão dois modos de inserção transversal do tema na escola (Wilde, 2000); o primeiro compreende a utilização ilustrativa de informações do campo da prevenção às DST/Aids a partir das disciplinas, por exemplo, se na aula de matemática cujo tema é proporção, podem-se usar dados epidemiológicos, mostrando percentuais de casos entre adolescentes. O segundo, corresponde à aplicação do conceito ampliado de tema transversal, que implica a construção de valores relacionados às

\footnotetext{
${ }^{5}$ Como exemplo para essas situações, a psicanalista Marlene Guirado relata uma história, em que uma criança tem um sonho com conteúdos relacionados à sexualidade. Na escola, a professora pede uma redação e a criança relata o sonho. A redação não é alvo de interpretações, discussão ou análise, a escola ofereceu o espaço e na perspectiva da autora isso já é o bastante.
} 
transformações das condições de vulnerabilidade no espaço das disciplinas.

No primeiro caso não se exige do professor uma reflexão de valores $e$ conceitos próprios. O necessário é distinguir os pontos de compatibilização entre os conteúdos úteis para a prevenção e os da disciplina em questão. Dessa forma, a escola atende à demanda operacional da saúde pública sem profundas revisões.

No segundo caso, a maior dificuldade é que esse processo não ocorre sem o engajamento pessoal dos docentes. É condição, a disposição para a reflexão e o aprendizado sobre os temas, além da disponibilidade pessoal para interagir com a comunidade escolar.

A proposta, que pretendemos fortalecer, segue esse último caminho mas, antes de chegarmos a este ponto, consideramos importante pensar sobre um aspecto específico e pouco problematizado que é a vulnerabilidade docente.

\section{Vulnerabilidade docente}

Considerando-se a educação como relação social, torna-se imperativo expandir a reflexão sobre a vulnerabilidade para além dos alunos e proceder, assim, a uma discussão sobre os elementos que constituem, hoje, a vulnerabilidade docente.

Contrariando o modelo moderno de mestre, no qual o professor, além do domínio de conhecimentos, deve ser um exemplo de comportamento, os Parâmetros Curriculares Nacionais, documentos que dispõem sobre as diretrizes para a Educação Sexual nas escolas, contêm um item denominado "Postura do Educador". Seu conteúdo expressa o desejo de que o educador seja capaz de reconhecer as múltiplas dimensões da sexualidade, trabalhar com essas questões e ainda, "ter discernimento para não emitir seus valores, crenças e opiniões como sendo princípios verdadeiros e absolutos" (Brasil, 1998c). Com uma discussão ancorada nas referências psicanalíticas, Mendonça Filho (1999) chama atenção para o fato de que a condição requerida ao professor é utópica, porque também ele é um sujeito e, portanto, passível de áreas de interdição sobre o sexual. Esse seria para o autor um nó crítico que estabelece limites evidentes para a educação sexual.

Assinalamos que, na literatura percorrida sobre prevenção e educação escolar, raramente era explicitada a preocupação em abordar diretamente a questão da vulnerabilidade docente, vendo essa como uma construção que integra fatores individuais e sociais com interface importante no processo de educação em saúde. A pergunta que aqui se coloca é que condições atuais limitam as possibilidades de os professores atuarem na prevenção às DST/ Aids?

Existem registros na literatura sobre um fenômeno emocional, o burnout que atinge diversos segmentos profissionais e que, para o caso dos educadores, foi descrita da seguinte forma:

O burnout é uma desistência de quem ainda está lá. Encalacrado em uma situação de trabalho que não pode suportar, mas de que também não pode desistir. O trabalhador arma, 
FONSECA, A.

inconscientemente, uma retirada psicológica, um modo de abandonar o trabalho, apesar de continuar no posto. Está presente na sala de aula, mas passa a considerar cada aula, cada aluno, cada semestre, como números que vão se somando em uma folha em branco. (Codo \& Vasquez-Menezes, 1999, p.254)

Em uma pesquisa realizada no Brasil, observou-se que 48,4\% dos educadores demonstraram vivenciar, pelo menos, um dos aspectos do burnout. As experiências que contribuem para isso, relacionam-se à perda de afetividade com o trabalho, o lugar de trabalho, os colegas de trabalho, que é potencializada pela competitividade; o descaso com a escola pública; os modelos de gestão que secundarizam as pessoas; a decadência salarial; a perda do respeito social (na comunidade e até na família); a imposição de currículos verticais que requerem criatividade simultaneamente à homogeneização dos contextos sociais; a carga horária esgotante etc.

O risco de não haver confronto com esta situação é a consolidação da escola como um espaço não criativo, portanto, incapaz de operar transformações. As alternativas, por mais que sejam revestidas de sugestões operacionais, requerem em sua origem, atitudes eminentemente políticas. Em linhas gerais, dizem respeito ao investimento no ensino público, nos cursos de formação de professores, além da mobilização de diversas instituições, incluindo as ONGs e universidades, entre outras, para que, em parceria com os setores da educação, contribuam para o planejamento $e$ execução de atividades de desenvolvimento profissional, além evidentemente do desenho de ações mais específicas com implantação a curto prazo.

\section{Vislumbrando uma vertente de atuação para a escola}

Ao considerarmos a sexualidade como um objeto de análise que deve ser observado em múltiplas dimensões, poderíamos afirmar que a escola e os professores devem qualificar-se tecnicamente para encaminhar essa discussão em todas essas dimensões, sob pena de estarem sendo reducionistas. Em relação à sexualidade, aí incluída a questão das DST/Aids, isso implicaria conhecer Psicologia, Psicanálise, Biologia, História para citar as disciplinas com as quais o tema é mais explicitamente relacionado.

Contudo, nossa proposta não é essa. Tratamos de escolher um eixo de reflexão/trabalho que tornasse essa discussão consistente e que permitisse a relação com os diversos aspectos que contribuem para reduzir a vulnerabilidade perante as questões de DST/Aids.

Esse eixo é a história e, em síntese, podemos dizer que sem perder sua especificidade, a escola e os professores de diversas disciplinas devem trazer para as salas de aulas e demais espaços escolares, os conhecimentos que permitem construir um saber sobre a sexualidade, sobre as doenças sexualmente transmissíveis e sobre as diferentes intervenções preventivas $e$ terapêticas que explicitem o fato de que esses campos foram historicamente construídos.

Quanto à sexualidade, podemos distinguir duas correntes de pensamento 
${ }^{6}$ Recentemente o

prefeito de uma cidade da Alemanha declarou o interesse em fazer uma operação de mudança de sexo. Os eleitores inciaram um movimento pela sua destituição, já que ele se tornara outra pessoa. Curiosamente esse tipo de questionamento raramente se dá mesmo diante a problemas que dizem respeito à gestão pública. Esse pensamento é claramente herdeiro da visão essencialista da sexualidade.

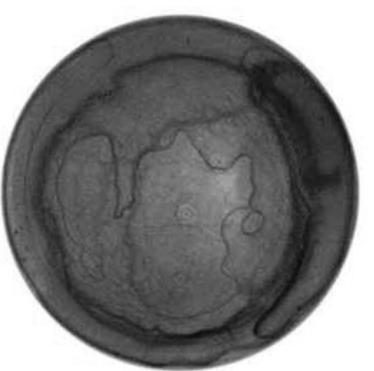

que apontam para formas diferentes de considerar essa questão: o essencialismo e o construcionismo histórico.

Por meio da visão essencialista, é possível explicar o todo a partir de um elemento que funciona como uma verdade interior. A identidade de um indivíduo seria então, definida a partir do modo como ele pode ser sexualmente classificado (Weeks, 1999). O pressuposto dessa visão é que o corpo expressa uma verdade fundamental e que a biologia é um destino ${ }^{6}$.

A visão de sexualidade como construcionismo histórico remete-nos ao pensamento de Foucault (1988, p.105), segundo o qual :
A sexualidade não deve ser pensada como um tipo de dado natural que o poder tenta manter sob controle, ou como um obscuro domínio que o conhecimento tenta gradualmente descobrir. Ela é o nome que pode ser dado a um construto histórico: não uma realidade furtiva que é difícil de apreender, mas uma enorme superfície em forma de rede na qual as estimulações dos corpos, a intensificação dos prazeres, o incitamento ao discurso a formação de um conhecimento especializado, o reforço de controles e resistências estão vinculados uns aos outros, de acordo com algumas poucas estratégias importantes de saber e poder.

Também em relação ao pensamento sobre sexualidade, tomando como referência a noção de construção social, existe uma diversidade de modos de pensar sobre as forças culturais que modelam a sexualidade e a forma pela qual o fazem. O denominador comum entre essas diferentes vertentes é o reconhecimento de que atos sexuais idênticos podem adquirir significados sociais inteiramente diferentes, em função de diferenças culturais ou históricas (Parker, 2000). Se não existe pois, uma relação fixa entre atos sexuais e identidades sexuais, o que existe são representações que variam culturalmente.

A discussão sobre a construção social da sexualidade prossegue, incorporando um questionamento sobre a inerência ao indivíduo de uma orientação sexual, ou se essa é também construída socialmente. As opções de resposta variam, considerando que a orientação é fixa $e$ o comportamento, construído culturalmente pela experiência subjetiva do indivíduo.

$\mathrm{Na}$ sua vertente mais extrema, o construcionismo social afirma que não existiria nada relacionado à sexualidade (impulso, orientação etc) que possa ser atribuído ao fisiológico.

Admitindo-se, como referência para nossa proposta de educação sexual, que a sexualidade é uma construção histórica, devemos, então, trazer ao debate nas escolas, a questão sobre o modo como determinadas características podem ser reconhecidas como marcas de identidade (Louro, 1999).

Quais seriam essas características que mereceriam destaque no debate escolar? Quais instituições sociais deveriam participar? De que forma tais instituições atuariam nessa produção? 
Neste ponto são temas relevantes os modos como se construíram as categorias de homossexualidade e de heterossexualidade; como foram construídos os padrões de normalidade sobre a idade certa para o relacionamento sexual e sobre que tipo de relação os legitima. De que forma esses padrões variam, não apenas no tempo e nas diferentes culturas, mas também como acontecem diferenças entre classes sociais.

Um campo amplo de discussão e que merece ser posto em pauta são as relações de gênero, esse concebido como diferenciação social entre homens e mulheres, ou seja, sob a forma de construção do masculino e do feminino. É necessário deslocar-se da perspectiva biológica para tentar dar evidência ao fato de que as diferenças e desigualdades entre os gêneros são construídas no espaço social, assim como mostrar que essas identidades não são polares, sendo necessário pensar em várias e diferentes mulheres, em vários e diferentes homens (Parker, 2000; Britzman, 1999; Louro, 1997).

Raras instituições não modelam essas identidades. Escola, Igreja, Família, Saúde Pública, Ciência e, mais insidiosamente, a Linguagem, por exemplo, atuam pedagogicamente, definindo o campo do desejável, aceitável, reprovável, saudável, estético etc.

Torna-se, então, extremamente pertinente que a escola promova a identificação das formas pelas quais essas produções de sujeitos corram evidenciando seu caráter permanente. Trazer a discussão da sexualidade para o âmbito público é quebrar a noção de que essa é uma experiência que se desenha exclusivamente no espaço individual, revelando sua trajetória no espaço social.

São inúmeros os debates que se originam deste campo, mas a escola que pretende desenvolver uma educação sexual não pode deixar de mobilizar-se em direção ao entendimento de que a escola atua sobre o corpo e sobre a sexualidade. Mobilizar-se para discutir como organiza-se em discursos sobre o feminino e o masculino, sobre o homem, a mulher e os estereótipos que se estabelecem socialmente (a propaganda e a literatura, por exemplo oferecem inúmeras oportunidades para essa discussão).

Não podemos porém, recomendar uma reflexão sobre a sexualidade que, de tão preocupada em preservar a especificidade da escola como forma de acesso ao saber científico, distancie-se do fato de que a sexualidade deve ser antes de tudo reconhecida como uma experiência prazerosa. Apostamos que a forma como são tratados esses assuntos também deve ter essa dimensão do prazer envolvido.

Acreditamos que o que se deve questionar, sobretudo através de nossa prática docente, é como se pode estimular o aluno. No caso de nosso interesse, o desafio é descobrir como se pode provocar no aluno o desejo de construir e integrar os conhecimentos na perspectiva de fortalecer um cuidado de si.

Supomos que um caminho fundamental a ser trilhado seja o de manter
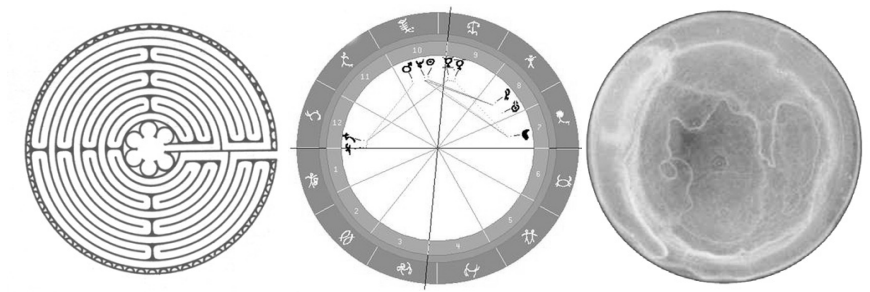
uma vinculação estreita com a realidade. Nesse sentido, é imprescindível o conhecimento sobre a realidade em que se insere especificamente cada grupo de 
alunos. Esse conhecimento deve dizer respeito não somente às características do segmento social dos alunos, mas também da comunidade a que pertencem, incluindo valores e hábitos culturais.

Trata-se, aqui, de fortalecer a visão segundo a qual o método didático seja estruturado a partir de dois eixos: o conteúdo e os sujeitos envolvidos na aprendizagem (Candau, 1990).

A partir daí, devem ser consideradas as alternativas práticas, admitindo que ser moderno não se reduz, nem se expressa, pela utilização de múltiplos recursos, mas, sobretudo, pela capacidade de refletir sobre as questões contemporâneas.

A primazia, então, não se dá sobre recursos e sim sobre a clareza de propósitos e a consistência das idéias, elementos de uma educação que se transforma e que se pretende transformadora.

No campo da sexualidade e das DST/Aids, inúmeros materiais têm sido produzidos e oferecem uma variedade grande de modos de fazer dinâmicas, inclusive, especificamente para adolescentes (Brasil, 1997). São instrumentos válidos que merecem ser criteriosamente analisados quanto a seus limites e possibilidades. Não são receitas universais que garantem mobilização afetiva e, assim, a elaboração de novas formas de se pensar o mundo. Por fim, deixamos registrado que esse não é um campo de conhecimento fechado; ao contrário, é mais um desafio para quem pretende continuar pensando, revendo e revelando novas formas de atuar.

\section{Considerações finais}

Em relação à educação sexual, o que a história nos mostrou é uma grande disponibilidade de associação entre a escola e o objetivo de corrigir os desvios da conduta humana, aí incluídos os de ordem sexual. Devemos chamar a atenção que, sob o argumento de urgência social, traduzidos em índices epidemiológicos, estamos, mais uma vez, correndo o risco de reeditar o aspecto mais tradicional e menos construtivo dessa interação entre o sexual $e$ a educação, muito embora travestidos com novos métodos e apoiados em discursos de indiscutível cientificidade.

A face mais visível dessa situação é a intensidade com que são incorporados os modelos educativos, que têm como pressuposto a identificação de comportamentos de risco e, como objetivo, a mudança de comportamento. Centradas no indivíduo, as práticas decorrentes dessa forma de compreender o processo saúde-doença reiteram a culpabilização desse mesmo indivíduo e esvaziam as possibilidades de diálogo que são condicionantes de uma estratégia de prevenção que pretenda promover o cuidado de si.

Confluindo para o fortalecimento dessa prática, insere-se a percepção de que os aspectos, que constituem a vulnerabilidade dos indivíduos, determinam nossa impossibilidade de estruturar um compromisso com a promoção à saúde. Desse modo, assim como as representações negativas que os docentes têm dos alunos torna-se um elemento a instituir o fracasso escolar, não situar criticamente os aspectos de vulnerabilidade como questões internas ao trabalho de prevenção pode reduzir a escola a uma 
função reprodutiva, incompatível com os propósitos que estão sendo para ela delineados no campo da saúde.

Valorizamos a alternativa que assume a sexualidade como construção historica, mediante discursos paralelos, que se combinam, excluem-se contradizem-se e são, fundamentalmente, oportunidades de reflexão. Sublinhamos a perspectiva histórica como um eixo de pensamento que pode concretamente perpassar as diversas disciplinas. Consideramos que, se cada disciplina oferece uma forma de abordar a questão da sexualidade e da prevenção as DST/Aids, poderá também mobilizar a atenção para o fato de que esses conhecimentos são também historicamente construídos.

Para finalizar, gostaríamos de articular as propostas de promoção à saúde a serem desenvolvidas por escolas com a proposta de revalorização da escola. Isso não se faz presente somente por referência a uma postura ideológica $e$ sim pela crença de que um espaço que, aos alunos, aparece como o espaço do descaso público, só em casos excepcionais poderá edificar-se como um lugar de criação de novas relações, com menos riscos e mais felicidade. E o impacto em saúde pública, todos nós sabemos, não se estabelece em torno de excepcionalidades.

\section{Referências}

AYRES, J. R. Vulnerabilidade e avaliação de ações preventivas. São Paulo: Casa de edição, 1996.

AYRES, J. R. Cidadania,vulnerabilidade e prevenção do HIV/Aids .In: PINTO, T.,TELLES, I.S. (Orgs.) Aids e escola: reflexões e propostas do EDUCAIDS.São Paulo:Cortez, 2000. p.21-28.

BALZAN, N. C. Sete asserções inaceitáveis sobre a inovação educacional. In: GARCIA, W. (Org.) Inovação educacional no Brasil: problemas e perspectivas. São Paulo: Cortez, 1989. p.265-83.

BARROSO, C., BRUSCHINI, C. Sexo e juventude: como discutir a sexualidade em casa e na escola. São Paulo: Cortez,1990.

BRASIL. Ministério da Saúde. Coordenação Nacional de Doenças Sexulamente Transmissíveis e Aids. Manual do multiplicador: adolescentes. Brasília, 1997.

BRASIL. Ministério da Saúde. Prevenir é sempre melhor. Proposta pedagógica, Brasília, 1998a. (Série um salto para o futuro)

BRASIL.Ministério da Educação e Desporto. Parâmetros Curriculares Nacionais: Saúde. Brasília, 1998b.

BRASIL. Ministério da Educação e do Desporto. Parâmetros Curriculares Nacionais: Orientação Sexual. Brasília, 1998c.

BRITZMAN, D. Curiosidade, sexualidade e currículo In : LOURO, G.L. (Org.) O corpo educado: pedagogias da sexualidade. Belo Horizonte: Editora Autêntica, 1999. p. 83-111.

CANDAU, V.M. A didática e a relação forma /conteúdo. In CANDAU, V.M. (Org.). Rumo a uma nova didática. Petrópolis: Vozes,1990. p.16-32.

CODO,W., VASQUES-MENEZES, I. O que é burnout? In: CODO, W. (Org.) Educação: carinho e trabalho. Petrópolis: Vozes, 1999. p.237-54.

ELIANE, C. Programas de prevenção em escolas: In: PINTO, T., TELLES, I.S.(Orgs.) Aids e escola: reflexões e propostas do EDUCAIDS. São Paulo: Cortez, 2000. p.129-38.

FOUCAULT, M. História da sexualidade: o cuidado de si. 9.ed. Rio de Janeiro: Graal, 1988. v.3.

GABE, J. Medicine, Health and Risk, Social Approaches. Londres: London University of London Press, 1995. 
GUIRADO, M. Sexualidade, isto é, intimidade: redefinindo limites e alcances para escolas. In: AQUINO, J.G (Org.) Sexualidade na escola: alternativas teóricas e práticas. São Paulo: Summus, 1997. p2542.

LOURO, G. Gênero, sexualidade e educação: uma perspectiva pós- estruturalista. Petrópolis: Vozes, 1997.

LOURO, G. L. Pedagogias da sexualidade. In: LOURO, G. L. (Org.) O corpo educado: pedagogias da sexualidade. Belo Horizonte: Ed. Autêntica, 1999. p.14-36.

MANN, J., TARANTOLA, D. J. M., NETTER,T. W. A AIDS no mundo. Rio de Janeiro: Relume- Dumará, 1993. p.275-300.

MENDONÇA FILHO, J. B. Será possível o sexual? In: DUNLEY, G. (Org.) Sexualidade e Educação: um diálogo possível. Rio de Janeiro: Gryphus, 1999. p.101-26.

PARKER, R. Na contramão da Aids: sexualidade, intervenção, política. Rio de Janeiro: ABIA; São Paulo: Editora 34, 2000.

SÃO PAULO. Secretaria Estadual de Educação. A prevenção na escola - relatos de experiências. São Paulo, 1999.

SAVIANI, D. Pedagogia histórico-crítica: primeiras aproximações. São Paulo: Cortez, 1999. (Polêmicas do nosso tempo)

SAYÃO, Y. Orientação sexual na escola: os territórios possíveis e necessários . In: AQUINO, J. G. (Org.) Sexualidade na escola: alternativas teóricas e práticas. São Paulo: Summus, 1997. p.107-17.

SILVA, T. T. Documentos de identidade: uma introdução às teorias do currículo. Belo Horizonte: Ed. Autêntica, 1999.

WEEKS, J. O corpo e a sexualidade. In: LOURO, G.L. (Org.) O corpo educado: pedagogias da sexualidade. Belo Horizonte: Autêntica, 1999. p.35-82.

WHO Technical Report Series 886. Adolescent development underlies the prevention of health problems. Geneve, 1998.

WILDE, J. Prevenção de Aids a partir de uma perspectiva curricular. In: PINTO, T.,TELLES, I. S. (Orgs.) Aids e escola: reflexões e propostas do EDUCAIDS. São Paulo: Cortez, 2000. p.145-53.

FONSECA, A. Prevención contra las enfermedades sexualmente transmisibles en el ambiente escolar, Interface - Comunic, Saúde, Educ, v.6, n.11, p.71-88, 2002.

La reflexión central de este artículo se constituye alrededor de las expectativas que pueden ser proyectadas en relación a las acciones educativas desarrolladas en escuelas en el ámbito de la prevención a las EST/SIDA. Para discutir este tema recurrimos a la revisión de los aspectos históricos que marcaron la institución de la educación sexual como contenido escolar. Registramos una intensa asociación entre la escuela y el objetivo de corregir los desvíos de la conducta humana, incluidos allí también los de orden sexual. Además, observamos que las propuestas de educación en salud formuladas en el área de la salud y dirigidas a la escuela establecen principios, objetivos y recomendaciones para la educación sexual de adolescentes y niños sin tematizar la escuela como espacio social. Finalmente señalamos que contribuciones altamente constructivas y de desarrollo factible en la escuela se dan, sobre todo, por la capacidad de abordar las categorías aparentemente fijas que constituyen el área de la experiencia de sexualidad como construcciones eminentemente históricas. Creemos que a partir de esa orientación se acentúa la posibilidad de readaptación de relaciones sociales que pueden originar impacto sobre las condiciones que amplían la vulnerabilidad de los individuos en relación a las enfermedades sexualmente transmisibles.

PALABRAS CLAVE: Síndrome de inmunodeficiencia adquirida; enfermedades sexualmente transmisibles; educación sexual; servicios de salud de los estudiantes. 
FONSECA, A.
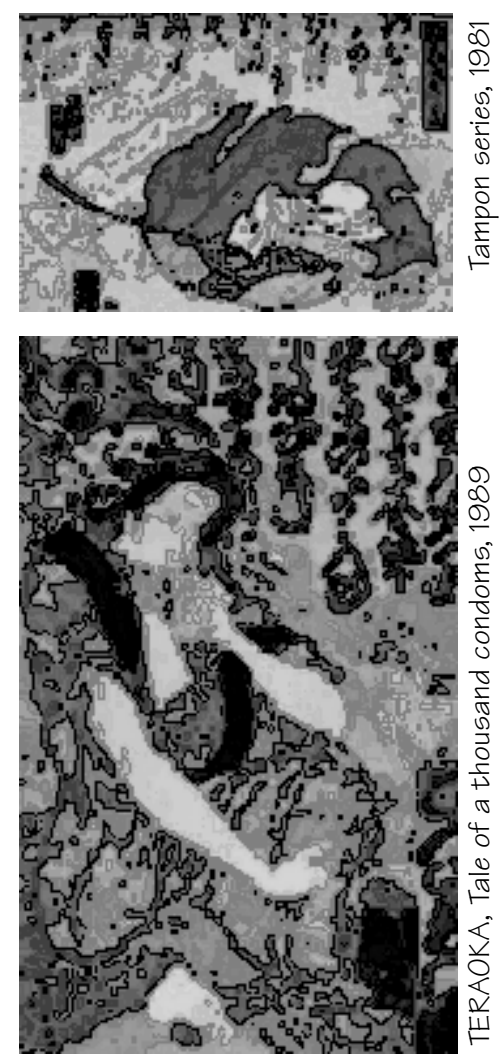

88 Interface - Comunic, Saúde, Educ, v6, n11, p.71-88, ago 2002 